\title{
KIRJANDUSTEADUS JA RAHVUS - MÕISTUS JA TUNDED
}

\author{
MÄRT VÄLJATAGA
}

$\mathrm{E}$ esti kirjandusteadusel pole tõenäoliselt olnud sama suurt mõju poliitilisühiskondlikule rahvuslusele (rahvustunnetele, riigiideoloogiale, „rahvusdiskursusele”) nagu ajalool, arheoloogial, folkloristikal ja keeleteadusel, ka mitte sama suurt nagu kirjandusel enesel. Viimased on andnud suurema panuse rahvuslikku eneseteadvusse ja narratiivi. Teisalt on rahvustunnete mõju kirjandusteadusele võib-olla suuremgi kui teistele humanitaarteadustele. Ka on suur osa kirjandusteaduse „sisendist” (uurimisaine, st autorid, teosed jm kirjandusnähtused) ja „väljundist” (uurimused ja nende adressaat) rahvuslik, st jääb eesti kultuuri piiresse. Kirjandusteaduse sisendi teoreetilised osad (mõisted, meetodid) on muidugi ka rahvusvahelised ning teaduse nüüdisaegne administreerimisviis kannustab rahvusvahelisemaks muutma ka väljundit. Sellise surve ja kirjandusteaduse rahvuskultuurilise tähtsuse vahel on aga pinge: mõlemat eesmärki ühekorraga täita on raske. Kirjandusteadusliku produktsiooni rahvusvaheline ja rahvuslik huviväärsus on teineteisest kas kaunis sõltumatud või lausa pöördvõrdelised. Selline ongi kokkuvõtlikult käesolevate uitmõtete lihtne, et mitte öelda triviaalne iva.

Teadus peaks põhimõtteliselt olema kõige mõistuspärasem vaimu- ja tegevusvaldkond, mida iseloomustavad objektiivsus, erapooletus, enesekriitika, külm pilk eikusagilt ning fakti ja väärtuse lahusus. Kuid nagu nii mõnigi filosoof on õpetanud, paljas mõistus ei suudaks meid motiveerida sõrmegi liigutama, kui seda ei käivitaks tunded. Teaduse puhul on peamisteks tunneteks muidugi teadmiskirg ehk uudishimu ning seejärel muud nii madalamad kui ka kõrgemad kired, soov kujundada inimeste maailmapilti ja leevendada nende kannatusi, aga ka armastus oma uurimisobjekti vastu ja selle vääristamine. Küllap kohtab viimast loodusteadusteski: keemikul ei tarvitse leiduda oma lemmikmolekuli, aga entomoloogil enamasti on oma lemmikputukas. Humanitaarteadlasel on peaaegu alati oma lemmikkultuur, kirjandusteadlasel lemmikkirjanikud. See teeb nad tundelisteks teadlasteks.

Humanitaarteaduste vajaduse tekitavad täppisteadused ise või õigemini nende tehnilised rakendused moodsas maailmas. Kui täppisteadused võtavad uurimise alla inimese, siis nad ühtlustavad ja puhastavad oma objekti või katseisikut (s.o subjekti), tõstes ta välja tema taustast, päritolust ja traditsioonidest. Tulemuseks on orientatsioonikadu. Näiteks üleni naturalistlik ja objektiivne täppisajalugu taandub kehade liikumise kummastatud ajalooks, millist parodeerib Lev Tolstoi „Sõjas ja rahus”: „Käesoleva sajandi alguse Euroopa sündmuste põhiliseks, oluliseks momendiks on Euroopa rahvaste masside sõjaline liikumine läänest itta ja seejärel idast läände” (1956: 290).

Moodsad humanitaar- ehk vaimuteadused tulevad mängu selleks, et orientatsioonikadu korvata ja muuta võõrandunud maailm jälle tuttavliku- 
maks. Seda on kenasti selgitanud hermeneutik Odo Marquard essees „Vaimuteaduste möödapääsmatusest" (1986). Vaimuteadused on tõlgendavad, jutustavad, orienteerivad ja skeptilised. Nad aitavad aru saada millegi tähenduslikkusest (nii semantilises kui ka tähtsuse mõttes). Lisaks sellele, et nad muude teaduste kombel avastavad, liigitavad ja seletavad fakte, formuleerivad seadusi, tuvastavad põhjusi, taandavad mitmekesisust mudelitele, valemitele ja skeemidele, jutustavad nad ka lugusid. Objektiivteaduslik vaade eikusagilt kustutab suunataju, sest kaovad isegi sellised eristused nagu vasak-parem ja all-ülal. Iga suund muutub samaväärseks, ükski pole teisest tähtsam. Orienteerivad vaimuteadused annavad meile suunataju tagasi. Vaimuteaduslik skepsis peaks aga tagama vaatepunktide paljuse ning vastuseisu ühehäälsusele, sest orienteerimisfunktsiooni võivad kuidagi ära täita ka müüdid, ideoloogiad ja kuulujutud. Alles metoodiline skepsis annab lugudele teaduslikkuse.

Millegi teadmisväärsust ennast pole lõppkokkuvõttes võimalikki teaduslikult põhjendada. Teadusteemade tähtsuse määrab nii teadussisene kui ka teadusväline vaatenurk. Head teadusteemad on sellised, mis sünnitavad uusi teadusteemasid (avavad perspektiive, tõstatavad küsimusi, süvendavad arusaamist jne) ning äratavad teadusvälise avalikkuse huvi oma rakenduslikkuse või kultuurilis-ajakirjandusliku huviväärsusega. Teemade valikut mõjutab tugevasti ka mood ja poliitiline konjunktuur. Thomas Kuhni kuulus teadusrevolutsioonide teooria, millele omal ajal heideti ette irratsionalismi, jääb humanitaarteadustele rakendatuna veel liigagi mõistuspäraseks. Humanitaarteaduse paradigmad ei vahetu mitte sisemiselt ammendudes, vaid sageli ajendab moe diktaat ja poliitiline konjunktuur alustatud ettevõtmisi ja kontseptsioone hülgama ning käsile võtma uusi ja atraktiivsemaid.

Max Weber kirjutab:

[---] võtkem ajaloolised kultuuriteadused. Need õpetavad mõistma poliitilisi, kunstilisi, kirjanduslikke ja sotsiaalseid kultuurinähtusi, lähtudes nende tekketingimustest. Ent nad ei anna iseendast vastust küsimusele: kas need kultuurinähtused olid ja on väärt olema? Ega vasta nad ka teisele küsimusele: kas tasub vaeva neid tundma õppida? Nad eeldavad, et seesugune osavõtt „kultuurinimeste” seltskonnast pakub huvi. Et asjad nii on, ei suuda nad „teaduslikult" kellelegi tõestada, ja see, et nad seda eeldavad, ei tõesta sugugi, et see on endastmõistetav. Tegelikult pole see sugugi nii. (Weber 1999: 1882)

Siin mainitakse kultuuriteaduste kaht eeldust, objekti väärtuse eeldust ja objekti uurimisväärsuse metaeeldust. Teoreetiliselt oleksid võib-olla mõeldavad ka spetsiifilisemad kombinatsioonid: eesti kirjandus on küll tähtsusetu (kunstiliselt ja ideeliselt alaväärne), aga mingil põhjusel on ikkagi tähtis seda käsitleda (näiteks kui millegi tähtsama õpetlikku sümptomit või selleks et paremini aru saada eestlastest nendega manipuleerimise eesmärgil). Või vastupidi: eesti kirjandus on küll väga tähtis, aga selle tähtsus on igaühele niivõrd enesestmõistetav, et seda polegi tarvis eriliselt uurida ega mõtestada - kirjandust tuleks pigem kummardada kui käsitleda.

Rahvusliku tähtsuse eeldus ja metaeeldus võivad uurijale ka teadvustamata jääda. Ta võib oma tegevuses lähtuda (sageli lähtubki) umbes sellisest 
kaalutlusest: eesti kirjandus (keel, ajalugu) ei lähe mulle korda mingil muul kui ainult sel põhjusel, et tegu on ainsa kirjandusega (keelega, ajalooga), mida ma oma piiratud tausta ja keeleoskuse ning allikatele ligipääsu tõttu uurida suudan. Või siis nii: eesti kirjandus pole küll uurimisväärne iseenesest, vaid ainult suure pildi killuna, võrdlusmaterjalina, mis aitab esile tõsta teatavaid üldinimlikke, kosmopoliitilisi ja ülemaailmseid nähtusi ja arenguid. Aga nagu me Pascalilt ja Tammsaarelt teame: korduvad tegevused kalduvad tahes-tahtmata sünnitama usku ja armastust. Niisiis enamasti lähtutakse eesti kirjanduse uurimisel nii eesti kirjanduse tähtsuse kui ka selle uurimise tähtsuse eeldusest. Mõlemad on väga rahvuslikud ja tundelised eeldused.

Lõppude lõpuks koosnebki ju inimmaailm rahvastest. Kõik rahvad pole rahvad küll päris ühtemoodi. Mõni on natsioon ehk rahvus, mõni „kõigest” etnos, rahvusrühm, suguharu, hõimuliit, klann jne - kas kõike korraga või ühte neist. Nad võivad asuda eri „arengustaadiumides”. Kultuur, usk, poliitika ja majandus mängivad igaühe siseelus natuke eri rolli. Rahvusele on teatavasti iseloomulikuks peetud ühist nime, riiki, keelt, territooriumi, kultuuri ja füüsilist tüüpi, mis kõik võivad paraku olla eri päritolu - luuletaja sõnutsi: „innud idast, maneerid läänest”. Ônneks on kirjandusteadus - erinevalt ajaloost, arheoloogiast, folkloristikast ja keeleteadusest - etnogeneesi tundlikest teemadest vabastatud. Eesti kirjandus on lihtsalt liiga noor. Heal juhul võib kirjandusteadusel olla midagi öelda „natsiogeneesi” kohta.

Etnos (või kui ka mitte etnos, siis populatsioon) ja natsioon suhtuvad teineteisesse analoogiliselt nagu inimese bioloogiline ja sotsiaalne sugu. Kuidas täpsemalt - selle kohta on saadaval laial skaalal teooriad, alates biologistlikest „paremal” kuni marksistlik-ökonomistlikeni „vasakul” koos mitmesuguste primordialismide ja konstruktivismidega vahepeal. Nii kirjandus kui ka rahvus on ühtviisi (kollektiivselt) subjektiivsed ja „konstrueeritud”, mis ei tee neid sugugi illusoorseks ega kahanda nende reaalsust. Kui poleks ainsatki subjekti, kes kirjandust loeks, poleks ka kirjandust. Kui poleks ainsatki subjekti, kes rahvust rahvusena teadvustaks, poleks ka rahvust.

Meil käibib kaunis sõna rahvusteadus ja seda isegi teadusbürokraatliku terminina. Tundub, et rahvusteadlastele endile see väga ei meeldi - osalt vist seetõttu, et võõrkeeltesse tõlgitult kõlab see imelikult. Urmas Sutrop pakub siiski definitsiooni: „[---] rahvusteadus on igasugune teadus, mis on seotud kultuuriga ja kohavaimuga, genius loci'ga, ning on mõjustatud selle maa põlisrahva keele kategooriate süsteemi omapärast ning mis annab panuse maailmakultuuri varasalve" (2012: 1172). Selles määratluses rahvust ennast mängu ei toodagi, kuid mööndakse pehme keelerelatiivsuse võimalust ning oodatakse teaduselt maailmakultuurilist tähtsust. Prantslaste ja inglaste erinevuste üle arutledes on Jaan Kaplinski märkinud: „Rahvuslik vaim ei kajastu täppisteadustes vähem kui kaunites kunstides” (1985: 999). Ja ta oletab, et inglise füüsikud, matemaatikud ja bioloogid on kaldunud - ei tea, kas keele kategooriate süsteemi omapära või genius loci tõttu - oma mõttekäike raamidest välja arendama, prantslased seevastu on olnud suured korrastajad.

Kui on juba võimalik prantsuse ja inglise rahvusliku ilmega füüsika, miks peaksid siis asjad olema teisiti pehmemates teadustes, sh rahvusluse uurimises? Eks rahvuslusteoreetikuidki mõjuta nende taust ja poliitiline kontekst: paljurahvuselised impeeriumid, rahvaste emantsipatsioonivõitlus, rahvusriik- 
luse ülesehitamine, natsionalismi ja internatsionalismi lubadused ja kuritarvitused. Neidki kujundavad rahvuslik vaim, ideoloogiaks vormunud soovid ja tunded. Mõni uurija oskab neid paremini kontrolli all hoida kui teine. Mõni ei üritagi ja mandub ideoloogiliseks propagandistiks. Edward Saidi kurikuulus raamat "Orientalism" (1978), mis süüdistas idamaade uurijaid imperialismi teenimises, alahindas õpetlaste iseseisva mõtlemise võimet ja puhta teaduse võimalikkust (kubisedes seejuures faktivigadest). Muidugi ei jää teadlased mõnikord imperialistlike tunnete ja soovmõtete vastu immuunseks. Aga kui nad pühenduksid jäägitult reflekteerimisele oma eelarvamuste, eelduste ja võimalike silmaklappide üle, jääks empiiriline töö viimaks tegemata.

Niisiis rahvustunded avaldavad mõju rahvusteadustele ning vastupidi. Mõlemasuunalised mõjud võivad olla nii hea- kui ka halvaloomulised. Võibolla mõnikord harva on teadused (etnograafia, ajalugu, populatsioonigeneetika - enamasti küll oma pseudoteaduslikumal kujul) aidanud kaasa rahvastevahelise vaenu õhutamisele ja põhjustanud kannatusi. Enamasti on selline vaen siiski küdenud juba enne omale „teadusliku” õigustuse leidmist.

Teinekord on rahvuslik soovmõtlemine viinud välja teaduslike narrusteni, kui armastus muudab uurija tegelikkuse vastu pimedaks, kannustab teda seal, kus allikad jm empiiriline materjal seda ei luba, postuleerima mitmekesisuse asemel ühtsust, tavalise asemel erilist, uudse asemel iidset, hilisuse asemel varasust, katkestuste asemel järjepidevust. See avaldub näiteks mitmesugustele esimustele, erandlikkustele jm maailmarekorditele pretendeerimisena. Nõukogude ajal pilgati neid šovinistlikke tendentse lausega: Venemaa on elevandi kodumaa.

Aga kirjandusteaduses pole needki tendentsid kuigi ohtlikud. Natuke narr see ju on, kui uurimistöö kogu aur läheb näitamisele, et meiegi pole olnud viimaste hulgas, et Tammsaare polnud mõni ajast ja arust realist, vaid hoopis modernist, isegi postmodernist! Et Kristian Jaak Peterson leiutas vabavärsi ühest tükist ja valmiskujul omast peast, et Juhan Liiv oli eksistentsialist avant la lettre või Underi ballaadid on Õhtumaa poeesia lõppjaam! Jaan Undusk on Stalini-aegse ajalookirjutuse kohta täheldanud: „Kõike „progressiivset” Eesti alal toimunut püüti kujutada ajalooliselt hilinenuna („alles siis”), kõige „regressiivse” olemasolu viidi aga tagasi võimalikult varasesse järku (,juba tollal")" (Undusk 2007: 20; pikemalt vt Undusk 2003). Samamoodi on võimalik eksida ka teisele poole.

Miks rahvustunnete mõju kirjandusteadusele on pigem süütu ja lausa paratamatu? Unduski essee „Retooriline sund Eesti nõukogude ajalookirjutuses” annab kaudse osutuse vastusele:

[---] iga tõsine ajalookirjutus on midagi enamat kui moraaliõpetus, aga iga ajalugu lakkab olemast, kui kaob tema moraal. Minevikukiri, mis ei sisaldaks mingeid moraalseid, ideoloogilisi, poliitilisi jne järeldusi oleviku jaoks, ei pakuks meile ka mingit huvi ja oleks õieti tunnetuslikult väärtusetu. [---] Niisiis pole moraal - või ideoloogia - mingi ajalookirjutusele olemuslikult võõras moment, millega ta mõnikord justkui vägivaldselt seotakse. Vastupidi, ajalookirjutus on just üks moraali- või ideoloogialoome olulisemaid valdkondi, kus tulemuslikkus sõltub sellest, kui hästi suudetakse veenda avalikkust mingi materiaalselt olematu asja või sündmuse moraalses tegelikkuses. (Undusk 2003: 41-42) 
Et kohaldada see mõttekäik kirjandusteaduse ja rahvusluse teemale, tuleks „ideoloogia” asendada „rahvuslusega” ning „moraalile” lisada veel „esteetilisus” ja „maitse”. Kirjandusteadus on küll midagi enamat kui maitsekriitika, kuid maitse kadudes see lakkaks. Lisaks tunnetuslikule ja moraalsele mõõtmele tuleb kirjandusteaduses ju veel mängu esteetiline mõõde. Teatavasti on kirjandusteaduses kolm läbipõimunud lõime: kirjanduse ajalugu, teooria (poeetika) ja kriitika (NB: mitte segi ajada arvustamisega!). Ükski ei saa läbi teisteta.

Kirjanduste o oria ehk poeetika eritleb kirjanduses avalduvaid korrapärasid, toob esile kirjandussiseseid sarnasusi, erinevusi, liigendusi ja liigitusi, pakub selleks vajalikke mõisteid, korrastades kirjanduskriitika tööriistu. $\mathrm{N}$-ö välispidine kirjandusteooria vaatleb üldistavalt ka, mida muu maailm (ühiskond, hing, keha, võim) teeb kirjandusele ja mida kirjandus muule maailmale.

Kirjanduslugu on osalt kultuuriloo osa, mis uurib, kes mida kirjutas, kes kellega käis, kes keda mõjutas, millised ühiskondlikud ja vaimsed jõud kirjanduses kajastuvad, milliseid jõude kirjandus on edendanud. See võib olla ka süsteemsem ettevõtmine: vormide ja võtete, teemade ja mõtete ajalugu, mis uurib kirjandussiseseid struktuurseid hüppeid ja longue durée'sid.

Humanitaarteadustele on omane historiseerimistung, kalduvus argumenteerida, et mõni nähtus, mida on harilikult peetud alati ja kõikjal olemasolevaks - kirjandus, lüürika, rahvus, sugu, armastus, teadvus vm -, on hoopis suhteliselt hilisaegne leidus. See tähendab, et mitte üksnes kirjandus (värsilised ja jutustavad tekstid) või rahvused ise (mitmesugused inimkollektiivid) on ajalooliselt arenenud, vaid et lisaks nende mõistete mahule (nähtustele, mida kirjanduse või rahvuse sildi alla koondatakse) on ajalooliselt muutunud ka mõistete sisu (tunnused, mille põhjal nähtusi vastavate mõistete alla viiakse). Muutlik on niihästi meie kontseptuaalse vaateklaasi värv ja kuju kui ka selle alla sattuvate asjade loomus. Seetõttu võib uurimustes ühtelugu põrgata esmapilgul põrpivatele väidetele, justkui oleks kirjandus, lüürika, armastus, sugu või rahvus tekkinud näiteks alles XVIII või XIX sajandil. Lähemal vaatlusel põrpivus kaob, kui väidete täpsustudes selgub, et silmas peetakse hoopis kirjandust, rahvust, armastust jne nende moodsas mõttes, nii nagu „meie neid mõistame”.

Kirjanduskriitika on kirjandusteoste tõlgendamine, nende tähenduse (sõnumi, tähtsuse, väärtuse) väljaselgitamine. Kirjanduse tõlgendamise vajaduse üheks eeltingimuseks võib olla ka see, et teosed ise ei suuda vahetult enda eest kõnelda, vaid vajavad publikule vahendamist, eksplitseerimist, interpreteerimist, avamist, mõtestamist. Seega on tõlgendusvajadus justkui languse saadus: nõukogude ajal kummardati kirjandust rohkem, tõlgendati vähem, nüüd vastupidi.

Kirjandusteooria on loogiline, kirjanduslugu empiiriline ettevõtmine. Kirjanduskriitika aga on selle tabureti kõige loomingulisem, pehmem, „ebateaduslikum" jalg (kui vahetada metafoori). Võib-olla pole olemas ainuõigeid tõlgendusi, aga kindlasti saab üks tõlgendus olla teisest parem ning leidub ka selgelt valesid ja absurdseid tõlgendusi. Muidugi pole kirjandusele ainuõigeid hinnanguid, aga mõni hinnang on teisest autoriteetsem, sest on istutatud parema maitse, veenvamate tõlgenduste, tuumakamate argumentide 
ja laiema eruditsiooni konteksti. Esteetilised otsustused pole kellelegi kohustuslikud. Neile ei pea alluma, nendega muganetakse (või ei muganeta). Kuid suur osa kirjanduse väärtusest pole üksnes esteetiline, vaid ka moraalset ja tunnetuslikku laadi.

Rahvustunded mõjutavad kirjandusteaduse kolme jalga natuke erinevalt. On kahtlane, kas vähegi sisukamas tähenduses oleks mõtet rääkida mingist „eesti teooriast”. Kirjandusteooria on üldiselt rahvusülene, läänelik nähtus. Kuid tähtsamad teoreetilised voolud on siiski olnud seotud rahvusliku ainega ja rahvuskirjanduslike probleemidega. Vene vormiteooria sündis vene kirjanduse uurimisest, Praha strukturalism ammutas oma materjali tšehhi kirjandusest jne. Ega teooria („üldistav terviklik mõistesüsteem, mis midagi kirjeldab ja seletab") pea tingimata olemagi üldinimlik ja üldkehtiv. Mõne tagasihoidliku praktilise eesmärgi jaoks võib luua ka väga kohaliku ja kitsa objekti keskse teooria (nt eesti riimi- või värsiteooria).

Kirjanduslugu on niisama suures osas rahvuslik üritus, nagu poeetika on rahvusvaheline. Samas uurib kirjanduslugu kindlasti ka kirjandussuhteid ning komistab mitmesugustele huvitavatele piirinähtustele, kus autorite keel, nimi, füüsiline tüüp, elukoht, adressaat jne võivad mingist norm-Eestist hälbida. Paljud stiilid, voolud, liikumised, võtted ja teemad on rahvusvahelised. Abstraktseks publikuks, mida eesti kirjanikud silmas peavad, võib olla ka kogu inimkond, tulevased sugupõlved või igaviku tribunal. Kuid vahetu ja konkreetne publik on eelkõige kohalik, kaasmaalastest lugejad. Jaan Undusk on kirjeldanud, kuidas alates XX sajandist on eesti kirjandus omandanud ka maailmakirjandusliku tahte: „muutuda eesti kirjandusena (ülesande esimene pool) kaasalööjaks maailmakirjanduse areenil (ülesande teine pool)" (1999: 249). Aga alati tahtmised ei teostu. Seetõttu ei ole meil palju selliseid maailmakirjanikke, keda saaks vähegi sisukamalt kirjand u s loolis elt mõtestada väljaspool nende rahvuslikku konteksti.

Kirjanduskriitika rahvuslikkus tuleneb otseselt kirjanduse rahvuslikkusest. Keegi ei keela meil Tammsaaret või Underit ükskõik kui suureks tõlgendada - isegi kui nende suurus ei seisne tingimata maailmakirjanduslooliste arengute esirinnas astumises. Marju Lepajõe (2017: 104) on maininud noore Unduski üleskutset ühes 1985. aasta ettekandes: „eesti kirjanduslugu tuleb kirjutada suureks”. Aga küllap pidas temagi silmas suureks kirjutamist esmalt meie enda jaoks.

Niisiis on eesti kirjandusteadus kõikidest teadustest kõige rahvuslikum, sest tema uurimisaine kui sisend on rahvuslik (meetod ei tarvitse küll olla) ja tema väljund - kirjatükid ja publik - on samuti valdavalt rahvuslik. Publikut on kolmesugust: 1) teised kirjandusteadlased, filoloogid, ajaloolased - kokku vaevalt sadakond inimest; 2) kultuurihuviline üldsus: ajaloo, mõtteloo, kirjanduse jm kunstide armastajad - kokku vaevalt tuhatkond inimest; 3) haridussüsteem - mõnikümmend tuhat last ja õpetajat koolis ja ülikoolis. Kirjandusteaduse mõju koolile on samas kõige pikema vinnaga ja vahendatum kui muud väljundid. Ja nii vist peakski olema, sest pole sugugi hea, kui kõik kirjandusteaduse moemuutused kohe ka õppekavva jõuaksid.

Neist väljunditest teaduse administreerimine suurt ei hooli, vaid lükkab rahvusteadusi rahvusvahelisemate väljundite poole. Põhjus on arusaadav. Väikerahva rahvusteaduste puhul on oht, et suletud süsteemis käivad kva- 
liteedikriteeriumid alla (konnatiigistumine) ja lõpuks tekivad hoopis mingid rahvuslikud ebateadused. Isegi suures NSV Liidus (ja väiksemas Rumeenias) jõuti eelmisel sajandil selle lähedale (nt marrism). Rohuks selle vastu peaks olema teaduse avamine rahvusvahelisele hindamisele, ingliskeelsus, koostööprojektid jms. Selle asemel et üksteise teadustööd hindaksid vaid mõni tosin eesti kirjandusteadlast või mõnisada kultuurihuvilist, võiks hinnanguandjate kogukond nõnda paisuda potentsiaalselt tuhandeteni. Meelevaldne subjektivism asendub nii aga formaalanonüümse subjektivismiga ning teaduse ratsionaalse maski alt paljastub masina irratsionaalsus, mida teadusšarlatanidel pole raske ära kasutada.

Kuidas aga saavutada Eesti-keskse sisendiga teaduse rahvusvaheline väljund? Siin tasuks pikemalt tsiteerida Jürgen Beyeri mõtisklust ajalooteaduse üle:

Muidugimõista ei räägi miski selle vastu, kui viljelda Eesti ajalugu tema enese pärast. Eesti ajalugu ei ole põhimõtteliselt vähem huvitav kui Prantsusmaa ajalugu, ja herderlikus mõttes on kõigi maade ajalugu ühevõrra tähtis.

Ometi ei harrastata ajalookirjutust ühiskondlikus vaakumis. Ajalugu on koolides õppeaineks, ja võimaluse tulevasi põlvkondi ajalooõppe kaudu ühes või teises mõttes mõjutada jätavad õppekavad Euroopas vaid haruharva kasutamata. Niikaua kui Eesti poliitikud peavad Eesti rahvusteadvuse edendamist olulisemaks euroopalike või kosmopoliitsete mõtteviiside viljelemisest, ei kao nõudlus rahvusliku ja Eestile keskendatud ajalooõppe järele kuhugi ka edaspidi ning ülikoolidelt tellitakse endiselt vastava kvalifikatsiooniga õpetajate koolitust.

Imelikul kombel esitab haridus- ja teadusministeerium samal ajal Eesti ajalooteadusele sootuks teistsuguseid nõudmisi - nii nagu ka ülejäänud teadustele. Eesti teadlased on kohustatud avaldama oma töid „maailma tasemel” rahvusvahelise mainega ajakirjades, nii nagu see on kombeks loodusteaduste puhul. [---] Niisuguste väljaannete veergudele pääsemiseks ja seega ka ministeeriumi bürokraatide nõudmiste täitmiseks on Eesti ajaloolastel vaid kaks teed. Esiteks võiks uurida [---] Eesti ajaloo asemel lihtsalt Inglismaa, Prantsusmaa, Saksamaa või Itaalia ajalugu (seejuures oleks siis juba kellegi teise asi rahvuslike ajaloomudelite sobivust kooliõppes teaduslikult õigustada). T e i s e ks võiks [---] valida uurimiseks selliseid probleeme, mille puhul oleks Eesti teemadel midagi rahvusvahelisele diskussioonile lisada. Eesti ülejäänud ajalugu jääks siis käsitlemata. Mingil juhul ei tasu aga loota, et rohkem kui peotäis välismaa spetsialiste hakkaks Eesti ajalugu pidama huvitavaks tema enese pärast. (Beyer 2009: 89-90, minu esiletõsted $-M . V$. Vt ka Beyer 2010)

Kogu see jutt kehtib mutatis mutandis ka kirjanduse uurimise kohta. Selle ees on niisiis järgmised võimalused: 1) orienteeruda rahvuslikule väljundile ja uurida eesti kirjandust tema enese pärast. Kui aga tahta, et väljund oleks rahvusvaheline, siis 2) uurida mõne muu rahva kirjandust, 3) valida eesti kirjandusest „uurimiseks selliseid probleeme, mille puhul oleks Eesti teemadel midagi rahvusvahelisele diskussioonile lisada". 
Millised need teemad võiksid olla? Laiemalt kultuuri uurimist silmas pidades arutati mõne aasta eest selle üle ühes vestlusringis, kus rõhutati eesti ainese piiripealsust, kultuurimuutuste kiirust (eriti tormiline moderniseerumine), allikmaterjali suurust ja kompaktsust (rahvaluulekogud) ning mõningaid käibeüldistusi kummutavaid erandeid (nt meesnõiad) (Kull, Lang 2015). Niisiis, kuna Eesti territoorium, eestlaste arv, aga ka eesti kirjanduspärand on suhteliselt väike, kompaktne ja läbitöötatav, siis oleks põhimõtteliselt võimalik mõni teema või nähtus enam-vähem a m mendavalt läbi uurida, nt analoogiliselt geenivaramuga kaardistada kogu eesti värsi või jutukirjanduse populatsioon. Milline peibutav väljakutse kvantitatiivsele digihumanitaariale! Paraku pole seda veel tõsisemalt käsile võetud.

Mida veel oleks kirjandusteadusel välisturule pakkuda? Rahvusliku teooria võimalikkus tundub kahtlane, rääkimata selle ekspordivõimest. Kirjanduskriitika ekspordivõime sõltub suurel määral tõlgendatava kirjaniku maailmakirjanduslikust tuntusest, mis peaks tõlgendusele eelnema. Enne tõlge, siis tõlgendus. Oskar Lutsu tõlgendusi tasub „maailmatasemel” teadusajakirjadesse pakkuda alles siis, kui Oskar Lutsu tõlked on „maailmatasemel” kirjastustes ilmunud. Vähesel määral saavad ingliskeelsed tõlgendused ka autori maailmakuulsusele kaasa aidata, aga loogilisem tee oleks alustada ikkagi tõlkimisest-tutvustamisest. Ja selles kunstis on kohalikel alati eelised: inglise kirjanduse parimad tutvustajad eestlastele on olnud eestlased ja eesti kirjanduse parimad tutvustajad prantslastele prantslased. See on pigem kultuuri- kui teadustegevus. Mis puutub kirjanduslukku, siis siin on võimalikud mitmesugused võrdlevad lähenemised, näiteks panuse andmine mingite rahvusvaheliste nähtuste (voolude, žanride, võtete) uurimisse nende kohalike avaldumiste käsitlemisega. Nii saaks näiteks kinnitada või kummutada maailmakirjandusliku protsessi oletatavaid seaduspärasid. Seejuures tuleks vältida imporditud kontseptsioonide ebakriitilist, mehaanilist, funktsioone ignoreerivat pealekleepimist kohalikule ainele. Mõisted tuleks pigem kohalikust ainest välja kasvatada, ehkki uurimuste ekspordivõimet võib tõsta hoopis vastupidine käik - kohalike üksiknähtuste otsing laenatud üldistuste illustratsiooniks.

Mingil juhul ei maksaks aga arvata, et see, mis on kirjandusteaduses ekspordivõimeline, oleks ühtlasi kultuuriliselt või rahvuslikult väga oluline ja huvitav. Teemad, millel on potentsiaali lisada midagi rahvusvahelisse diskussiooni, ei tarvitse olla eesti kirjanduse uurimise seisukohalt kõige kesksemad. Ja eesti kirjanduse uurimise seisukohalt tähtsatel teemadel võib puududa vähimgi ekspordipotentsiaal.

P.S. See 2017. aasta augusti koosolekuks koostatud jutt leidis endale ootamatu puändi hilissügisel, kui ajalehtedesse jõudsid teated, et teaduse hindamisel on nüüd tähtsaks kriteeriumiks tõusnud societal impact, mille mõtestamisega humanitaarid olevat jänni jäänud (Ojasaar 2017; Himma 2017 jm). Termini väljamõtlejate algseid taotlusi ignoreerides võiks kirjandusteaduses seda meie oludes vabalt tõlkida „rahvuskultuuriliseks mõjuks”. Millisele ühiskonnale siis veel saaks kirjandusteadus mõju avaldada? (Seejuures näib hindajate optimistlik eeldus olevat, et igasugune mõju on tingimata healoomuline.) Kui rahvusvahelisuse nõudmisele oli võimalik vastata, et eesti kirjan- 
dusteaduse (resp. -kriitika) väljund on paratamatult eelkõige rahvuslik, siis nüüd me näeme, kuidas bürokraatiatont on juba ka selle väljapääsu hõivanud ja nõuab sealgi tõhusamat mõõtmist ja mõtestamist. Loodetavasti andis eelöeldu kirjandusteaduse ühiskondliku mõju mõtestamisse väikese panuse.

\section{Kirjandus}

B eyer, Jürgen 2009. Mis teeb Eesti luterluse kultuuriajaloole huvitavaks? Tlk Vahur Aabrams. - Vikerkaar, nr 7-8, lk 79-90.

B eyer, Jürgen 2010. Otium reficit vires ja humanitaaride töötingimused. Tlk Vahur Aabrams. - Sirp 22. X.

Himma, Marju 2017. Akadeemik: Kõik Euroopa riigid on hädas teaduse mõju mõõdupuu hindamisega. - ERR.Novaator, 18. XII. http://novaator.err.ee/649014/ akadeemik-koik-euroopa-riigid-on-hadas-teaduse-moju-moodupuu-leidmisega

Kaplinski, Jaan 1985. Kirjandusliku karakteristika katse. - Looming, nr 7, lk 998-1001.

Ku 11, Kalevi, Lang, Valter 2015. Piiride rikkus ja muutuste mustrid: Eesti ainest võib pidada teaduslikult plahvatusohtlikuks. [Vestlusring] - Sirp 23. I.

Le p ajõ e, Marju 2017. Substantsiga kahekesi. - Vikerkaar, nr 3, lk 101-106.

Marquard, Odo 1986. Über die Unvermeidlichkeit der Geisteswissenschaften. - O. Marquard, Apologie des Zufälligen. Philosophische Studien. Stuttgart: Reclam, lk 98-116.

Oj a s a r, Krista 2017. Kuidas mõõta humanitaarteaduste ühiskondlikku mõju? [Vestlusring.] - Sirp 21. XI.

Sutrop, Urmas 2012. Kuidas me mõistame rahvusteadust? - Akadeemia, nr 7, lk 1155-1177.

Tolstoi, Lev 1956. Kogutud teosed neljateistkümnes köites. VI köide. Sõda ja rahu. Tlk M. Sillaots, V. Linask. Tallinn: Eesti Riiklik Kirjastus.

Und u sk, Jaan 1999. Eesti kirjanduse ajast, ruumist ja ülesandest XX sajandil. Teese kommentaaridega. - Looming, nr 2, lk 249-255.

Und u sk, Jaan 2003. Retooriline sund Eesti nõukogude ajalookirjutuses. - Võim \& kultuur. Koost Arvo Krikmann, Sirje Olesk. Tartu: Eesti Kirjandusmuuseum, Eesti kultuuriloo ja folkloristika keskus, lk 41-68.

Und u sk, Jaan 2007. Ajalookirjutusest Eestis ja eksiilis Teise maailmasõja järel. Võhiku mõtted. - Tuna, nr 1, lk 4-26.

W eb er, Max 1999. Teadus kui elukutse ja kutsumus II. Tlk Henn Käärik. - Akadeemia, nr 9, lk 1878-1894.

\section{Literary studies and the nation - sense and sensibility}

Keywords: literary studies, humanities, nationalism, academic publishing and administration

The "societal impact" of Estonian literary studies on political and cultural nationalism (nation building, national discourse) has not been as big as corresponding impact of historiography, archeology, folkloristics, and linguistics, not mentioning 
literature itself. Disciplines dealing with ethnogenesis and political history have contributed more to the national narrative. On the other hand, national sentiments have probably had even bigger influence on literary studies than on any other branch of humanities. Large parts of the input (authors, works and other literary phenomena) and output (essays and their public) of literary research are national, being confined to the Estonian culture. The theoretical parts of input (concepts, methods) are, of course, partly international. The methods of administration of scientific research encourage strongly the internationalisation of output as well. But as most of the important Estonian authors enjoy only local renown, only some very specific aspects of Estonian literary studies have export potential. Between the pressure of internationalisation and national-cultural significance of literary research there is a tension, and it is difficult to pursue both aims at once. The international and national interest of literary scholarship is quite independent of each other or even inversely related.

Märt Väljataga (b. 1965), cultural magazine Vikerkaar, editor, mart@vikerkaar.ee 